\title{
Levantamento das práticas de programação detalhada da produção: um survey na indústria paulista
}

\author{
A survey on detailed production scheduling in \\ manufacturing plants in São Paulo, Brazil
}

\author{
Edivaldo Giacon ${ }^{1}$ \\ Marco Aurélio de Mesquita ${ }^{1}$
}

\begin{abstract}
Resumo: Devido à grande instabilidade dos mercados e a intensa competição entre as empresas, a Programação Detalhada da Produção (PDP) vem se tornando cada vez mais um desafio para a gestão empresarial. As empresas, na busca do aprimoramento das atividades de PCP, estão demandando ferramentas de programação finita, também conhecidas como Advanced Planning and Scheduling (APS). Este artigo visa identificar as necessidades e dificuldades da programação detalhada da produção, as barreiras de implantação e os benefícios dos sistemas APS. O método utilizado foi um survey com as empresas filiadas à Fiesp. Os resultados obtidos mostram: i) a programação detalhada da produção é efetivamente uma atividade complexa para a maioria das empresas, especialmente aquelas com estratégia de produção contra pedido (MTO-make to order); ii) a maioria das empresas ainda utiliza o modelo MRP (capacidade infinita); iii) os objetivos de melhoria de desempenho na entrega poderiam ser mais facilmente alcançados com o uso de sistemas APS; iv) o investimento financeiro e falta de capacitação são ainda impedimentos para a implantação desses sistemas.
\end{abstract}

Palavras-chave: Programação da produção. Capacidade finita. APS. MRP. ERP.

\begin{abstract}
Due to the instability of markets and the intense competition among companies, detailed scheduling has increasingly become a challenge to management. Companies that focus on the improvement of PPC activities demand tools to meet their needs, such as the finite capacity scheduling tool, also known as Advanced Planning and Scheduling System (APS) to improve delivery times, effective scheduling, and control of the firmed order. This paper aims to identify the needs and difficulties of the detailed production scheduling, the critical factors for implementation, and the benefits that the advanced scheduling systems (APS) can provide. The method used was a survey of companies affiliated to the Federation of Industries of São Paulo (FIESP). The results showed that the detailed production scheduling is a complex activity for most companies, especially for those that adopt make to order strategy (MTO). The majority of companies surveyed use the MRP planning model, but their goals can be more easily achieved with the use of advanced programming systems (APS). Financial costs and lack of training are still limiting factors to implementing those systems.
\end{abstract}

Keywords: Production scheduling. Finite capacity systems. APS. MRP. ERP.

\section{Introdução}

Desde a década de 1990, muitas empresas têm adotado sistemas ERP para controlar e integrar as informações dos processos de negócios das empresas referentes aos clientes, fornecedores, recursos humanos, custos e fluxo de caixa. As atividades de gestão de estoques, gerenciamento de pedidos, planejamento e controle da produção, distribuição, contabilidade e gestão de recursos humanos são os processos mais beneficiados pela implantação de sistemas ERP nas empresas.
Helo (2008) realizou um survey com as empresas fornecedoras de sistemas ERP na Finlândia que aponta como vantagens proporcionadas pelos sistemas ERP: redução do lead time, 22\%; melhoria na data de entrega, $17 \%$. Quanto às limitações dos sistemas ERP: dificuldade de entendimento da lógica ERP, 46\%; complexidade, $36 \%$; dificuldade de implantação, $36 \%$. Portanto, vale destacar a importância de ferramentas mais apropriadas e amigáveis para atender às necessidades da atividade de planejamento e controle da produção.

\footnotetext{
${ }^{1}$ Departamento de Engenharia de Produção, Escola Politécnica, Universidade de São Paulo - USP, Av. Prof. Almeida Prado, 531, CEP 05508-070, Butantã, São Paulo, SP, e-mail: giacon@usp.br; marco.mesquita@poli.usp.br
} 
Metaxiotis, Psarras e Ergazakis (2003) relatam a falta de ferramentas adequadas para a atividade de planejamento e programação da produção. Diante dessa carência, muitas empresas têm buscado sistemas de programação finita para resolver esse problema. Durkin (1996) realizou um survey com as 500 maiores empresas norte-americanas e verificou que $35 \%$ consideravam a atividade de programação como a mais importante aplicação na área de sistemas de gestão empresarial.

Na maioria dos sistemas ERP, utiliza-se um módulo MRP para gestão da manufatura, que tem por objetivo reduzir os investimentos em estoque, procurando adquirir e disponibilizar os materiais para a produção na quantidade necessária e no momento certo.

Os sistemas MRP assumem que os lead times e estoques de segurança são fixos e não ajustam as datas planejadas das ordens com base na carga do chão de fábrica (HOPP; SPEARMAN, 2000). Devido às suas hipóteses simplificadoras, o MRP não atende perfeitamente às necessidades de programação detalhada da produção.

Conforme Dumond (2005), em função dos ambientes de produção serem dinâmicos, dois problemas-chave são: prover datas realistas para os clientes na negociação dos pedidos e, a partir dos pedidos firmes, gerar programas de produção que atendam à demanda com a utilização eficiente dos recursos. Vários problemas podem ocorrer na produção (quebras de equipamentos, atrasos na entrega de materiais, necessidade de horas extras em centros críticos, falta de visibilidade do chão de fábrica, etc.), tornando as atividades de programação e controle da produção bastante complexas.

Nos atuais Sistemas Integrados de Gestão Empresarial (ERP), o módulo de programação detalhada da produção não atende plenamente às necessidades dos usuários (METAXIOTIS; PSARRAS; ERGAZAKIS, 2003). Os sistemas APS (Advanced Planning and Scheduling), ainda novos e pouco explorados (STADTER; KILGER, 2005; JONSSON; KJELLSDOTTER; RUDBERG, 2007), surgem como alternativa para resolver problemas mais complexos de planejamento e controle da produção.

Os fornecedores de software APS (PREACTOR; QUINTIQ; LINTER; ASPROVA; ORTEMS; TAYLOR; PPI-MULTITASK) preconizam que a ferramenta traz muitas melhorias para as empresas: redução dos estoques de produtos acabados, redução de estoques de materiais em processo, melhorias no atendimento dos pedidos, redução de imprevistos, redução de ociosidade de recursos, melhor gestão de compras de materiais e serviços, melhoria nas relações com clientes e fornecedores.

Segundo Pedroso e Correa (1996, p. 11), a implantação de um sistema de programação da produção com capacidade finita, integrada aos demais módulos do sistema de ERP, pode capacitar a empresa a melhorar o desempenho em:

- custos: relacionados à utilização e variação da capacidade produtiva - o que pode resultar em um aumento da capacidade produtiva disponível -, e à manutenção dos níveis de estoques de matérias-primas, em processo e de produtos acabados, adequados à política de planejamento da produção da empresa;

- velocidade de entrega: que diz respeito à redução dos tempos de fluxo e consequentemente, à diminuição dos tempos de entrega percebidos pelos clientes;

- pontualidade nos prazos de entrega acordados: referentes à melhoria da definição dos prazos junto aos clientes (ao menos, considerando a negociação sob a ótica da programação da produção) e cumprimento destes;

- flexibilidade de volume e de entrega: que está relacionada ao aumento da habilidade da empresa em se adaptar às mudanças não previstas na demanda e nos recursos produtivos;

A respeito da seleção de um sistema APS, Pacheco e Santoro (2001) identificaram as seguintes deficiências como principais no processo de avaliação: i) avaliação deficiente das oportunidades de melhoria do sistema atual; ii) investigação deficiente de alternativas existentes; e iii) análise deficiente da relação entre aderência e qualidade da solução. Em resposta a essas carências, Pacheco e Cândido (2002) propõem uma metodologia que tenta minimizar estas questões e está organizada em quatro etapas: i) avaliação das oportunidades de melhoria e seleção preliminar de alternativas; ii) análise detalhada de aderência e qualidade de solução dos modelos; iii) ponderação dos resultados obtidos entre os modelos; iv) análise de critérios comerciais e estratégia de implantação.

$\mathrm{O}$ conceito de capacidade finita proporcionou uma nova geração de ferramentas de programação e controle da produção, capazes de considerar diversas variáveis e restrições. Vários artigos discutem sua aplicação e implantação em diferentes ambientes produtivos (GRAVES, 1981; WIERS, 2002; METAXIOTIS; PSARRAS; ERGAZAKIS, 2003; DUMOND, 2005; JONSSON; KJELLSDOTTER; RUDBERG, 2007; LIN; HWANG; WANG, 2007).

Nas empresas brasileiras, observa-se também uma preocupação cada vez maior com o tema desta pesquisa e é crescente o número de empresas que vêm implantando e usando um software específico para programação detalhada da produção.

Assim, verificam-se os seguintes pontos: 
- relatos da complexidade e dificuldades da programação detalhada da produção (PDP) nas empresas;

- a consolidação do modelo MRP, ainda que não atenda plenamente às necessidade de PCP;

- as empresas não utilizam ferramentas adequadas para PDP;

- dificuldades de implantação e custos elevados de sistemas de gestão da produção.

Especificamente, este trabalho tem por objetivo identificar as necessidades e dificuldades da programação detalhada da produção, as barreiras de implantação e os benefícios que os sistemas APS podem proporcionar.

O artigo está estruturado em cinco seções. A segunda e terceira seções apresentam o referencial teórico dos sistemas de programação da produção e o método de pesquisa. A quarta seção traz os resultados do survey e sua discussão. A última seção discute as limitações e desdobramentos do presente estudo.

\section{Sistemas de programação detalhada da produção}

Neste tópico, apresenta-se uma breve revisão bibliográfica sobre programação detalhada da produção, os sistemas MRP, JIT e OPT e suas limitações, os sistemas APS e os sistemas de controle da produção (MES-Manufacturing Execution Systems).

Hopp e Spearman (2000) resumem os objetivos para a programação detalhada da produção em: entregar os produtos na data acordada, maximizar velocidade de fluxo e minimizar ociosidade dos recursos. No entanto, estes objetivos são conflitantes entre si, assim, a meta da programação detalhada da produção é contribuir para o aumento da lucratividade das empresas contrabalançando os conflitos destes objetivos.

O principal objetivo de um sistema de programação da produção é gerar um programa que atenda às exigências dos clientes, condicionadas à disponibilidade de recursos definida no planejamento mestre da produção. Seu nível de agregação trata de componentes e produtos acabados, e seu horizonte de planejamento estende por alguns dias ou semanas, em ambientes produtivos com grande mix de produtos e muitos roteiros alternativos.

Decidir qual a melhor ferramenta para programação detalhada não é tarefa fácil. Metaxiotis et al. (2003) estabeleceram um framework para escolha da melhor ferramenta de programação, na qual se deve mapear o sistema de produção e identificar as características específicas do sistema de produção, os objetivos prioritários de programação e os requisitos especiais da produção e dos clientes.
Para avaliar a eficácia da programação detalhada, utilizam-se algumas medidas de desempenho (LUSTOSA et al., 2008):

- Tempo de fluxo das ordens: é o intervalo entre a liberação e a conclusão da ordem de produção, incluindo esperas, tempos de preparação (setups), movimentações entre estações, atrasos resultantes de quebra de equipamentos, indisponibilidade de equipamentos, etc. Minimizar o tempo de fluxo contribui para redução de custo (estoques mais baixos) e, evidentemente, do tempo de entrega (velocidade de fluxo);

- Tempo total de processamento (makespan): é o tempo total para concluir um grupo de tarefas. Minimizar o tempo total também contribui para redução dos custos e tempos de fluxo, conforme mencionado anteriormente;

- Atraso total: é o somatório do atraso de um grupo de tarefas em relação aos prazos de entrega acordados. Minimizar o atraso total está relacionado às prioridades competitivas de custo, qualidade (serviço insatisfatório) e tempo (entrega pontual);

- Estoque em processo: corresponde à quantidade de ordens abertas. Além do efeito positivo na qualidade e produtividade dos processos, a redução do estoque em processo contribui para aumentar a velocidade de fluxo das ordens;

- Utilização: razão entre o tempo efetivamente utilizado e o tempo total disponível do recurso. O aumento da utilização implica na redução dos custos de produção.

\subsection{Sistemas MRP, JIT e OPT}

O modelo MRP é caracterizado como um sistema de produção "empurrada", que gera as ordens de produção e compra, conforme o programa mestre de produção, as listas de matérias (BoM-Bill of Materials) e os níveis de estoque (LAURINDO; MESQUITA, 2000). A partir dos lead times de produção e compra, determinam-se os instantes em que as ordens devem ser liberadas, aplicando uma lógica de programação para "trás".

Taal e Wortmann (1997) relatam que a variação de demanda em curto espaço de tempo não pode ser resolvida com excesso de estoques e trabalho em horas extras e tradicionalmente o MRP não consegue resolver estes problemas, por considerar lead time fixo e não detectar restrições de capacidade. Para resolver estes problemas, as empresas estão caminhando para sistemas de capacidade finita (APS).

Laurindo e Mesquita (2000) relatam que as limitações do MRP são: o MRP trabalha com o conceito 
de "janelas de tempo", que não permite representar, em detalhe, as sequências das operações na fábrica. Os lead times são considerados parâmetros e estimados estatisticamente; no cálculo de necessidades, são utilizados como se fossem constantes, independentes da carga da fábrica e do tamanho dos lotes. Imprecisões nas estimativas destes tempos podem levar ao aumento dos estoques intermediários, quando superestimados, ou interrupção da produção por falta de material, quando subestimados.

A viabilidade do programa gerado pelo MRP é verificada por meio do carregamento dos centros de trabalhos e a comparação com as respectivas capacidades. Portanto, a grande limitação do sistema MRP está no fato de não garantir uma programação detalhada da produção viável nos centros críticos. Quando constata uma sobrecarga, não apresenta alternativas de solução do conflito de capacidade. Cabe, então, ao planejador antecipar ou atrasar as ordens ou ainda contratar horas extras.

Outra limitação do MRP está na lógica de prioridade baseada na data do pedido, ignorando outras opções, como número de trocas de ferramentas, tempo de set up, prioridade do cliente. O MRP trabalha com o conceito de capacidade infinita, que não detecta gargalos produtivos e considera lead-time fixo. Para um maior detalhamento sobre MRP, recomenda-se a leitura de Hopp e Spearman (2000, cap. 4).

Em contraposição aos sistemas MRP, estão os sistemas de produção puxada, dentre os quais se destaca o pioneiro Just-in-Time (JIT), um dos pilares do Sistema Toyota de Produção. O nivelamento da produção (heijunka) e o uso de cartões kanban constituem dois fundamentos do JIT diretamente relacionados ao PCP, Hopp e Spearman (2000, cap. 5).

A lógica do JIT consiste em gerenciar os estoques na fábrica como em um supermercado, no qual os produtos são repostos apenas quando consumidos pelos clientes. A sinalização do consumo é feita com os cartões kanban, que indicam o produto, centro de produção, tamanho do lote e outras informações técnicas.

Francischini e Heckert (1998) resumem que o sistema JIT consolida-se com alguns pressupostos básicos que precisam funcionar plenamente: redução dos tempos de preparação, padronização das operações, reorganização do arranjo físico da fábrica, utilização de uma força de trabalho qualificada com programa de qualidade robusto para não gerar retrabalho, trabalhar com pequenos lotes e com baixa variação de demanda.

Corrêa, Gianesi e Caon (2001) relatam que as principais limitações do JIT referem-se à necessidade de que a demanda seja razoavelmente estável, para que se consiga balancear os recursos; complexidade dos roteiros de produção e grande variedade de produtos são também limitadores. Hopp e Spearman (2000) destacam que, muitos mais que um procedimento técnico, o JIT é uma filosofia de produção, que reúne um conjunto de técnicas e princípios, mas não o reconhecem como um sistema de planejamento da produção.

Outra abordagem de programação da produção é o OPT (Optimized Production Technology), que consiste em um algoritmo de programação finita da produção orientado para maximização do fluxo no recurso crítico ou gargalo. Este conceito evoluiu para a "Teoria das Restrições", que inclui uma filosofia de melhoria contínua, uma proposta de sistema de avaliação de desempenho e um módulo de programação e controle da produção baseado no recurso gargalo. O método de programação e controle, denominado drum-buffer-rope (DBR), consiste basicamente em: programar o recurso gargalo-tambor (drum); dimensionar estoque intermediário para proteção do recurso crítico-pulmão (buffer); puxar a produção a partir do recurso gargalo-corda (rope). O sistema DBR caracteriza-se pelo uso de técnicas de programação finita e um mecanismo de produção puxada. Um maior detalhamento sobre DBR pode ser obtido em Goldratt e Cox (2002).

Observa-se que não existe uma técnica aplicável a todos os casos, cada empresa deve tentar encontrar uma solução que seja compatível com sua estratégia de produção para que tenha resultados satisfatórios. Corrêa e Gianesi (1993) analisam os modelos MRP, JIT e OPT em detalhes, explorando também a combinação destes em sistemas híbridos de PCP.

\subsection{Sistemas APS}

O conceito APS é relativamente novo e sua aplicação vai desde o nível estratégico até o operacional (programação de chão de fábrica), dessa forma procura-se considerar todas as restrições existentes com o objetivo de maximizar os objetivos de desempenho, utilizando regras de sequenciamento, heurísticas e métodos de otimização.

Os sistemas APS complementam os sistemas ERP, tipicamente transacionais, oferecendo maior suporte aos processos de decisão. Destacam-se as seguintes características dos sistemas APS: são ferramentas de suporte à decisão; são sistemas que podem simular diversos planos e programações com diversas restrições, permitindo a geração de planos otimizados; resolvem problemas complexos de planejamento, utilizando métodos heurísticos, programação linear, etc.; são sistemas com grande velocidade de processamento, mas requerem um hardware dedicado (GUNTHER; BEEK, 2003). O Quadro 1 apresenta uma comparação entre os sistemas APS e MRP.

Um dos objetivos principais dos sistemas APS é a determinação exata do programa de produção, 
Quadro 1. Comparação entre sistemas MRP e APS.

\begin{tabular}{|c|c|c|}
\hline Tópico & MRP & APS \\
\hline Abordagem & $\begin{array}{l}\text { Planejamento sem considerar a capacidade } \\
\text { dos recursos para a execução do plano }\end{array}$ & $\begin{array}{l}\text { Planejamento fornece um plano exequível } \\
\text { baseado nas limitações dos recursos }\end{array}$ \\
\hline Foco & Coordenação da manufatura & Satisfação da demanda dos clientes \\
\hline Aplicação & Manufatura discreta & Engloba diferentes indústrias \\
\hline Natureza & Transacional & Analítico \\
\hline Abrangência & $\begin{array}{l}\text { Financeira, contábil, } \\
\text { manufatura, RH }\end{array}$ & $\begin{array}{l}\text { Cadeia de suprimentos } \\
\text { (compras, produção e entrega) }\end{array}$ \\
\hline $\begin{array}{l}\text { Capacidade de } \\
\text { Simulação }\end{array}$ & Baixa & Alta \\
\hline $\begin{array}{l}\text { Capacidade de } \\
\text { otimização }\end{array}$ & Baixa & Alta \\
\hline $\begin{array}{l}\text { Velocidade de } \\
\text { processamento }\end{array}$ & Baixa & Alta \\
\hline
\end{tabular}

Fonte: adaptado de Entrup (2005).

respeitando as principais restrições referentes à disponibilidade de materiais e máquinas. Os sistemas APS consideram restrições de matéria-prima, ou seja, planejam a entrega de matéria-prima somente quando ocorre a necessidade e utilizam técnicas da teoria de scheduling (pesquisa operacional), como minimizar o custo de setup, cumprir prazos de entrega, minimizar o WIP, minimizar o lead-time, entre outras.

Cabe ressaltar que os sistemas APS consideram os requisitos de material e capacidade da planta, respeitando os objetivos da empresa, e geram um sequenciamento viável, algumas vezes otimizado, ao contrário do sistema MRP, que apresenta um único passo, assumindo capacidade da planta infinita.

A Figura 1 apresenta os principais módulos dos sistemas APS. A seguir, apresentam-se os objetivos principais de cada módulo.

- Planejamento da Rede - determina a estrutura da Cadeia de Suprimentos no horizonte de planejamento, incluindo localizações de fábricas e centros de distribuição (horizonte de planejamento de 3 a 5 anos).

- Planejamento da Demanda - determina as metas e orçamentos de vendas com base nos dados históricos, considerando os ciclos de vida dos produtos e informações de diferentes áreas da empresa. Na operação, encontra-se o módulo de gerenciamento de pedidos e atendimento à demanda dos clientes.

- Planejamento Mestre - este módulo do nível tático tem como objetivo equilibrar a demanda com a capacidade, tendo como resultado o Programa Mestre de Produção - MPS.

- Compras e Administração de Materiais - gestão de estoques de matérias-primas e fornecedores.
- Programação Detalhada da Produção - a programação detalhada da produção é gerada, respeitando a disponibilidade de capacidade e materiais, conforme as diretrizes do MPS.

- Planejamento de Distribuição e Transportes no planejamento de curto prazo, verifica a disponibilidade de estoques e transporte para gerar a programação das entregas.

\subsection{Manufacturing execution systems}

No último estágio da hierarquia do PCP estão as atividades de execução e controle do chão de fábrica, que compreendem três atividades principais: i) liberação das ordens; ii) sequenciamento das operações; e iii) apontamento da produção (FERNANDES; GODINHO FILHO, 2010). Para execução desta etapa, há os sistemas de controle conhecidos como SFC (Shop Floor Control) ou MES (Manufacturing Execution System).

Os sistemas MES são sistemas de informação que coletam dados do chão de fábrica como tempos de setup e operação, quantidades de produtos produzidos ou estágios das operações em tempo real. As empresas utilizam estes dados para atualizar seus sistemas de planejamento e programação e com isso obter vantagens competitivas. Esses sistemas acoplam-se aos demais sistemas gerenciais, como o ERP e o APS; complementam os sistemas ERP, que não seriam capazes de lidar com aspectos como andamento de uma ordem de produção enquanto ela está em processamento e sujeita às incertezas da produção.

\section{Método de pesquisa}

Este trabalho busca um melhor entendimento das práticas adotadas pelas empresas de manufatura na 


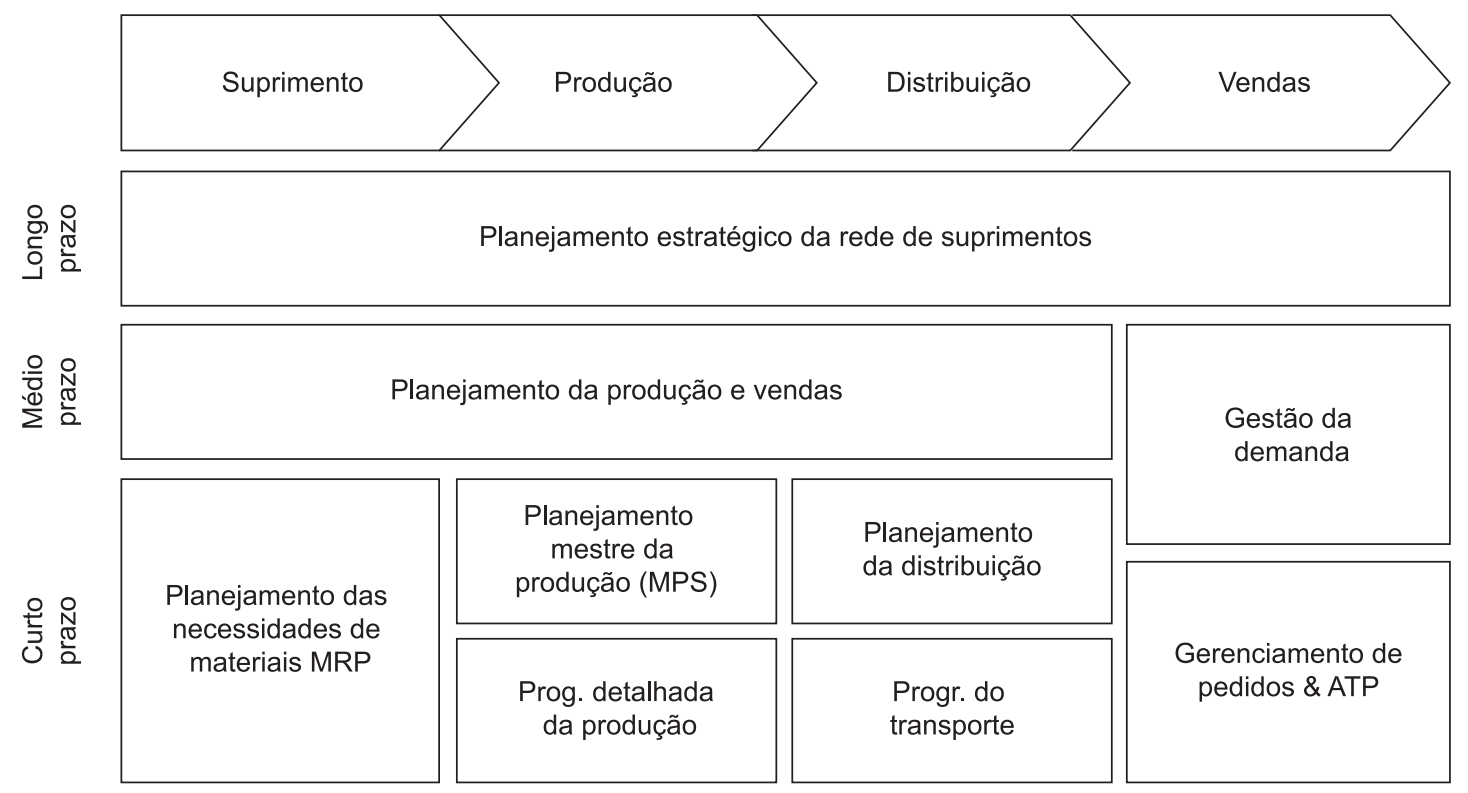

Figura 1. Estrutura de sistema APS. Fonte: adaptado de Gunther e Beek (2003).

atividade de programação detalhada da produção. Especificamente, esta pesquisa pretende verificar o uso de modelos/lógicas de planejamento da produção; o estágio da empresa em relação ao uso da tecnologia de informação para atividade de planejamento e controle da produção; os critérios adotados para a programação detalhada e controle da produção no chão de fábrica; os principais problemas e dificuldades encontradas para a atividade de programação da produção, mapeando esses fatores nas empresas associadas à Fiesp. A partir destes objetivos, foram formuladas às seguintes questões de pesquisa:

- Q1: As empresas realmente necessitam de uma ferramenta de programação finita (APS) para a programação detalhada da produção?

- Q2: Quais são as barreiras para implantação dos sistemas APS?

- Q3: Quais são os benefícios dos sistemas APS para as empresas?

Definidas as questões de pesquisa, o passo seguinte consiste na formulação das hipóteses que, a priori, poderiam responder as questões propostas e que servem para orientar as etapas subsequentes do projeto de pesquisa (Leedy, 2000).

Segundo Forza (2002), as hipóteses estabelecem relações lógicas entre duas ou mais variáveis, descritas como afirmações que podem ser testadas. Para a primeira questão, formula-se a seguinte hipótese:

- H1: Os sistemas APS complementam o MRP, que não atendem plenamente às necessidades de planejamento da produção das empresas de manufatura.
Para as questões 2 e 3, de caráter mais exploratório, não serão formuladas hipóteses a priori. Definidas as questões de pesquisa e a hipótese a ser testada, discute-se o método de pesquisa, que neste estudo seguiu, em linhas gerais, os passos propostos por Forza (2002), conforme Figura 2.

Em relação ao método de Forza (2002), não houve um tratamento estatístico formal dos dados, sendo as evidências avaliadas qualitativamente apenas.

Pretende-se verificar a hipótese de que o uso de ferramentas de programação finita integradas ao MRP melhoraria o desempenho da produção. Para este estudo, considera-se, dentro da Classificação Nacional de Atividades Econômicas (CNAE), a indústria de transformação, representada no intervalo de códigos de 10 a 33 .

Definidos os objetivos e dados a serem coletados, o próximo passo consiste no desenvolvimento do instrumento de coleta de dados.

Conforme Leedy (2000), utilizou-se um guia para validação do questionário para relacionar as perguntas da coleta de dados com as questões de pesquisa e identificar qual o melhor tipo de pergunta.

Após sua elaboração, o questionário foi validado em duas empresas: uma farmacêutica, que já tinha implantado o APS, e outra empresa fornecedora de APS.

O questionário é formado por 21 questões divididas em três seções. Na primeira delas, a intenção é caracterizar o ambiente de produção, verificar o estágio atual e a tendência da programação detalhada da produção. O objetivo desta seção do questionário foi verificar os objetivos de desempenho, a estratégia de produção e os sistemas de informações gerenciais 


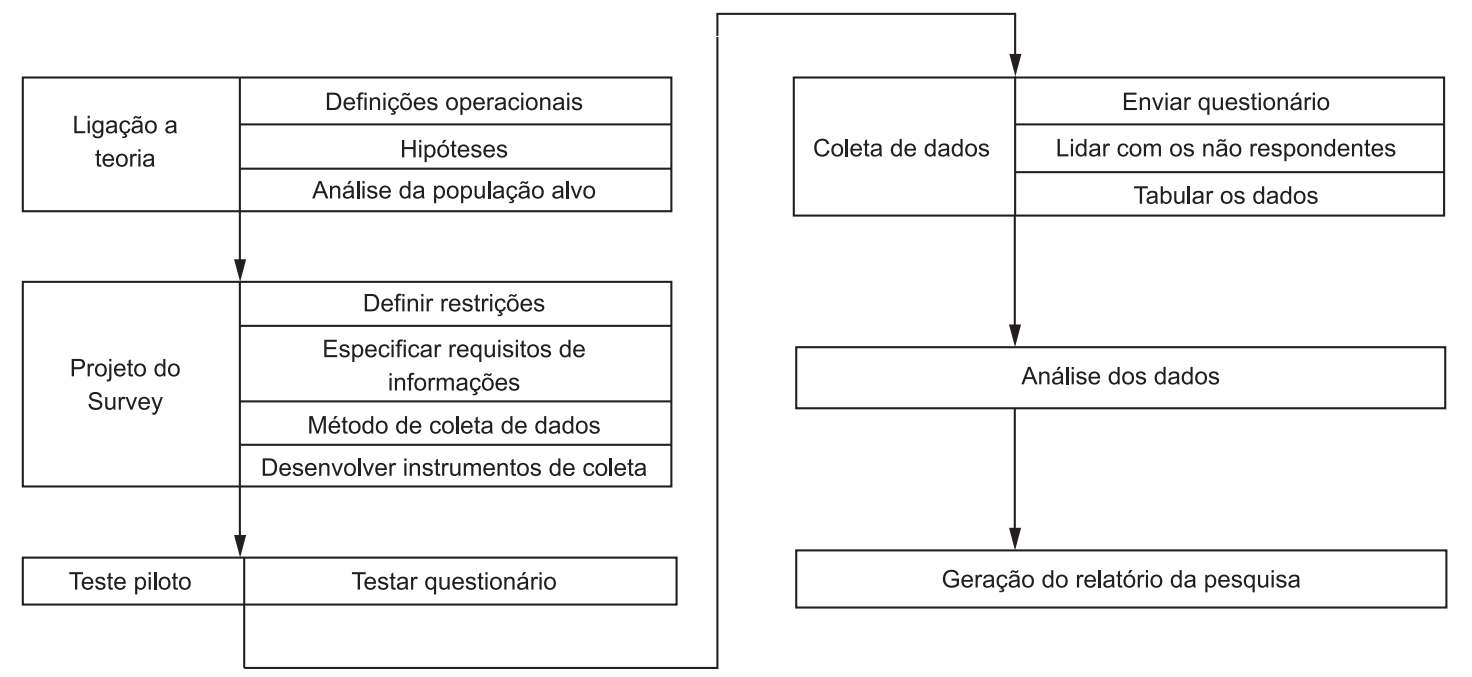

Figura 2. Etapas de estruturação de uma survey. Fonte: adaptado de Forza (2002).

utilizados para atividade de planejamento e controle da produção. A segunda seção do questionário procura avaliar a utilização dos sistemas de informações gerenciais, a capacitação e o conhecimento dos usuários. O objetivo dessa seção é verificar os modelos de planejamento, avaliar se os modelos atendem às necessidades das empresas consultadas e quais sistemas estão sendo utilizados com maior frequência. E, por fim, a terceira seção do questionário traz a caracterização dos respondentes e possíveis comentários sobre o tema da pesquisa. Após a conclusão da versão final do questionário, solicitou-se o apoio da Federação das Indústrias do Estado de São Paulo (Fiesp) para encaminhar o questionário aos respondentes por meio de sua mala direta.

A coleta de dados foi realizada via internet. Um primeiro $e$-mail convite para participação na pesquisa, contendo um link para o questionário, foi enviado pela Fiesp aos associados. A pesquisa "ficou no ar" durante três meses, com duas chamadas adicionais, tendo resultado em 94 questionários preenchidos corretamente de um total de 95 recebidos. Os autores não tiveram contato direto com os respondentes, exceto dois contatos telefônicos feitos voluntariamente por dois deles.

\section{Discussão dos resultados}

A análise dos resultados é realizada pelo cruzamento das perguntas do questionário com as questões de pesquisa. Dez perguntas do questionário são referentes à Q1 (As empresas realmente necessitam de uma ferramenta de programação finita (APS) para a programação detalhada da produção?); seis perguntas associadas à Q2 (Quais são as barreiras para implantação dos sistemas APS?); duas perguntas relacionadas à Q3 (Quais são os benefícios dos sistemas APS para as empresas?), além de quatro perguntas para caracterização da empresa e do respondente.

\subsection{Caracterização das empresas pesquisadas}

A Tabela 1 apresenta a distribuição do ramo de atividades das empresas respondentes (CNAE 10...33), estratificada pela estratégia de produção dominante. Dentre as empresas participantes da pesquisa, destacam-se as empresas do setor de fabricação de máquinas e equipamentos e as empresas com estratégia de produção MTO.

O levantamento possibilitou traçar o perfil dos respondentes também quanto ao faturamento bruto anual. Constatou-se que $48 \%$ são de empresas de pequeno porte (até $\mathrm{R} \$ 50$ milhões), $21 \%$ de médio porte (entre R \$ 50 milhões e R \$ 250 milhões) e 30\% de grande porte (acima de $\mathrm{R} \$ 250$ milhões).

Quanto ao perfil dos respondentes: 69\% eram diretores e gerentes da área de planejamento da produção e logística, o que indica uma preocupação gerencial com o tema em questão.

\subsection{Discussões dos resultados referentes à $\mathrm{Q} 1$}

As perguntas de 1 a 6, 8, 9, 13 e 16 do questionário referem-se à questão de pesquisa Q1 (As empresas realmente necessitam de uma ferramenta de programação finita (APS) para a programação detalhada da produção?). As perguntas estão relacionadas aos objetivos de desempenho para atividade de Programação Detalhada da Produção (PDP), utilização de Sistemas de Informação Gerenciais (SIG), qual o modelo/lógica de planejamento em uso, ferramenta 
Tabela 1. Respondente por ramo de atividade.

\begin{tabular}{lccc}
\multicolumn{1}{c}{ Ramos de atividade } & MTO & MTS & Total \\
\hline Fabricação de máquinas e equipamentos & 10 & 6 & 16 \\
Fabricação de produtos de metal exceto máquinas e equipamentos & 7 & 3 & 10 \\
Fabricação de produtos de borracha e de material plástico & 6 & 3 & 9 \\
Confecção de artigos de vestuário e acessórios & 4 & 2 & 6 \\
Fabricação de produtos alimentícios & 0 & 6 & 6 \\
Fabricação de produtos farmoquímicos e farmacêuticos & 2 & 3 & 5 \\
Fabricação de equipamentos de informática, produtos eletrônicos e ópticos & 2 & 2 & 4 \\
Fabricação de produtos químicos & 1 & 3 & 4 \\
Metalurgia & 3 & 1 & 4 \\
Fabricação de máquinas, aparelhos e materiais elétricos & 2 & 0 & 2 \\
Fabricação de móveis & 2 & 0 & 2 \\
Fabricação de outros equipamentos de transporte exceto veículos automotores & 1 & 1 & 2 \\
Fabricação de produtos diversos & 1 & 1 & 2 \\
Fabricação de artefatos de couro, artigos para viagem e calçados & 1 & 0 & 1 \\
Fabricação de coque, de produtos derivados do petróleo e de biocombustíveis & 1 & 0 & 1 \\
Fabricação de produtos têxteis & 1 & 0 & 1 \\
Fabricação de veículos automotores, reboques e carrocerias & 1 & 0
\end{tabular}

utilizada na PDP e posição quanto à implantação de uma ferramenta de programação finita.

Iniciando com os objetivos de desempenho, as empresas responderam que redução de custo e entrega no prazo e nas quantidades acordadas são os objetivos de maior importância (Figura 3).

A pesquisa apontou que $67,2 \%$ dos respondentes estão satisfeitos com os sistemas de informações gerenciais. Os ERP são sistemas transacionais e não de apoio à decisão. No estudo de Metaxiotis; Psarras e Ergazakis (2003), constata-se que os sistemas de informações gerenciais não atendem plenamente às necessidades de programação detalhada da produção. No que tange à lógica/modelo de planejamento da produção, a maioria das empresas respondentes identifica o sistema em uso com uma das duas versões do modelo de MRP (Figura 4).

As ferramentas utilizadas para a programação detalhada da produção são predominantemente planilhas eletrônicas e poucos utilizam um sistema de programação finita.

Os respondentes dão maior importância para o cumprimento do prazo de entrega, seguido da prioridade do cliente e menores tempos de setup, objetivos que podem ser melhor alcançados com o uso de uma ferramenta avançada de programação (Figura 5).

As empresas na estratégia de produção MTO são as que mais necessitam de uma ferramenta de programação detalhada. Pelo levantamento, verifica-se que 50\% pretendem implantar. Apenas 10 empresas estão utilizando um sistema APS e, dentre estas, nenhuma relatou insatisfação com o uso do sistema depois de implantado (Tabela 2).

A hipótese a ser testada para a Q1 é:

- (H1) Os sistemas APS complementam o MRP, que não atendem plenamente às necessidades de planejamento da produção das empresas de manufatura.

Pelos dados coletados, constata-se: o uso predominante do MRP; os usuários estão satisfeitos com os sistemas de informações gerenciais; uma boa parte pretende implantar o sistema APS e, para os poucos usuários na amostra, os APS contribuem para melhorar o cumprimento de prazos, redução de lead times e aumento de utilização da capacidade. Com base nestes dados, aceita-se a hipótese H1, a hipótese de que os sistemas APS são complementares ao MRP e podem contribuir para melhoria da PDP.

\subsection{Discussões dos resultados referentes à Q2}

No que diz respeito à Q2 (Quais são as barreiras para implantação dos sistemas APS?), as perguntas relacionadas a esta questão são $(10,11,12,14,16$ e 17) e abordam o software utilizado, tempo de uso, ferramenta de apontamento e dificuldades de implantação.

As empresas que implantaram o APS (Preactor, Drummer, APO-SAP, Glovia foram citados) utilizam estes sistemas há relativamente pouco tempo (até 5 anos). 


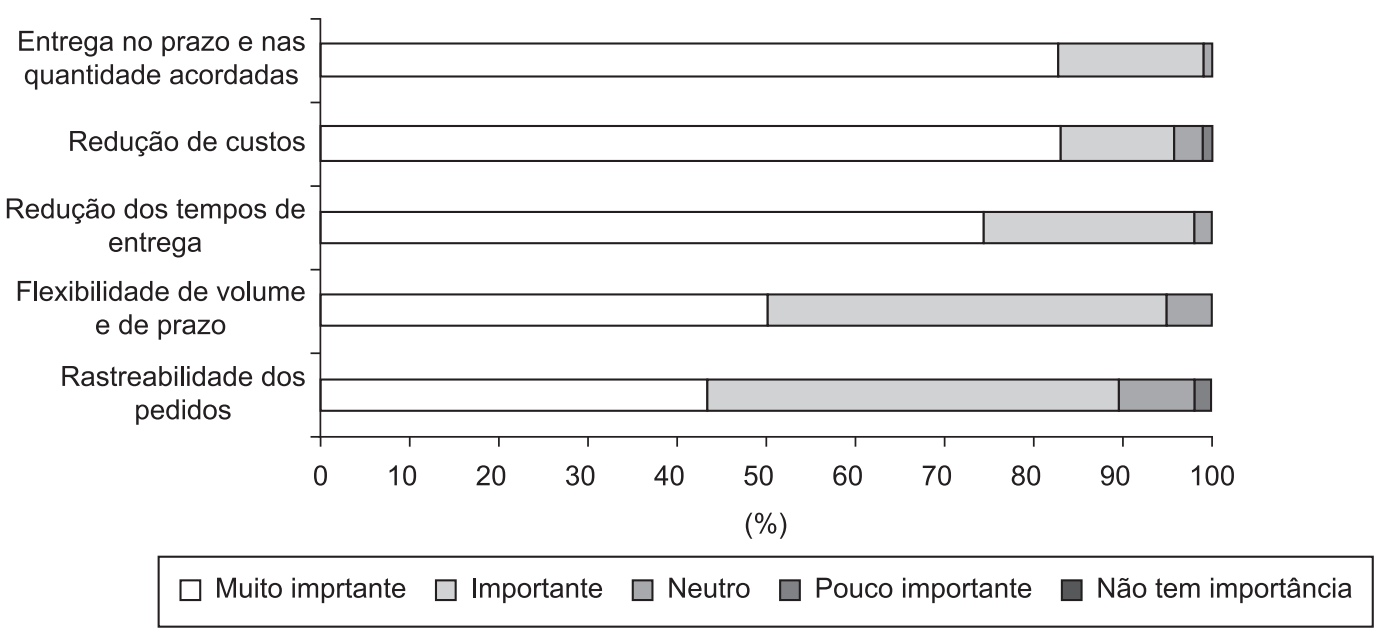

Figura 3. Objetivos de desempenho para a atividade de PCP.

Tabela 2. Evolução para um APS.

\begin{tabular}{|c|c|c|c|c|c|c|}
\hline Estágio & \multicolumn{2}{|c|}{ MTO } & \multicolumn{2}{|c|}{ MTS } & \multicolumn{2}{|c|}{ Total } \\
\hline Não implantou e não pretende implantar & 23 & $41,8 \%$ & 24 & $61,5 \%$ & 47 & $50,0 \%$ \\
\hline Não implantou, mas pretende implantar & 22 & $40,0 \%$ & 14 & $35,9 \%$ & 36 & $38,3 \%$ \\
\hline Implantou, mas não obteve resultados e não pretende reimplantar & 0 & $0,0 \%$ & 0 & $0,0 \%$ & 0 & $0,0 \%$ \\
\hline Implantou e utiliza, mas ainda não conseguiu resultados satisfatórios & 4 & $7,3 \%$ & 0 & $0,0 \%$ & 4 & $4,3 \%$ \\
\hline Implantou e utiliza com resultados satisfatórios & 4 & $7,3 \%$ & 0 & $0,0 \%$ & 4 & $4,3 \%$ \\
\hline Em processo de implantação & 2 & $3,6 \%$ & 0 & $0,0 \%$ & 2 & $2,1 \%$ \\
\hline Não Responderam & 0 & $0,0 \%$ & 1 & $2,6 \%$ & 1 & $1,1 \%$ \\
\hline Total & 55 & $100 \%$ & 39 & $100 \%$ & 94 & $100 \%$ \\
\hline
\end{tabular}

Um fator crítico para a efetiva implantação do APS na empresa diz respeito ao apontamento das ordens de produção na fábrica. A Tabela 3 apresenta as práticas de controle da produção nas empresas pesquisadas. Verifica-se que o uso de sistemas automatizados (MES), que potencializam o uso do APS, ainda é pouco difundido. $\mathrm{O}$ apontamento manual ou por terminal de computador nas ordens de produção constituem o padrão em controle da produção.

O Quadro 2 apresenta as maiores dificuldades citadas pelos respondentes para implantação de um sistema APS. Como o número de empresas na amostra que implantou sistemas APS é baixo (apenas 10 entre 94), os resultados obtidos aqui, neste aspecto, podem não ser significativos, mas apontam alguns pontos para reflexão.

\subsection{Discussões dos resultados referentes à Q3}

No que diz respeito à questão de pesquisa Q3 (Quais são os benefícios dos sistemas APS para as empresas?), as perguntas diretamente relacionadas são a 7 e a
Quadro 2. Dificuldades para implantação do APS pelas empresas.

\begin{tabular}{|l|}
\hline \multicolumn{1}{|c|}{ Dificuldades Apontadas } \\
\hline Customização de procedimentos \\
Apontamento de horas no chão de fábrica \\
Cadastros desatualizados \\
Integração com os sistemas legados \\
Disciplina em cumprir o planejado \\
Adaptação do usuário \\
Convencer a alta admininstração de \\
um sistema complementar \\
\hline
\end{tabular}

15 do questionário (avaliação do sistema ERP e as principais dificuldades encontradas na PDP).

As empresas responderam que os sistemas ERP atendem às expectativas quanto ao planejamento $\mathrm{e}$ controle da produção (Tabela 4). Confrontando estes resultados com os da Tabela 2, pode-se inferir que, na perspectiva dos respondentes, a programação detalhada da produção não é atribuição dos sistemas ERP e sim dos APS, reforçando a complementaridade destes sistemas. 


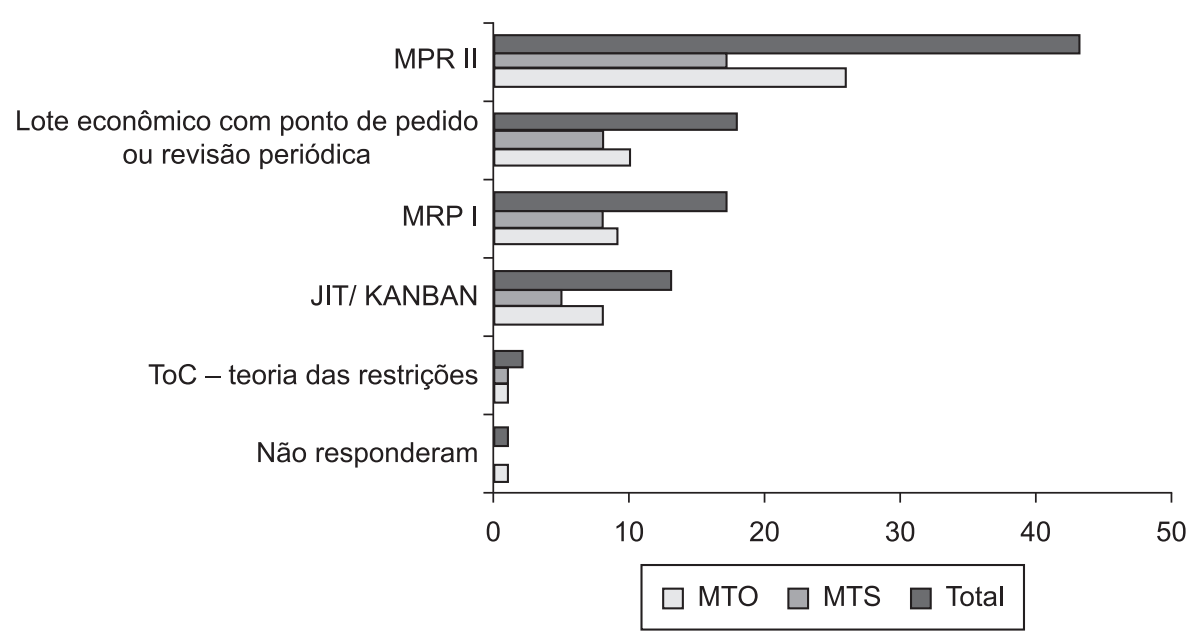

Figura 4. Modelo ou Lógica de Planejamento citados pelos respondentes.

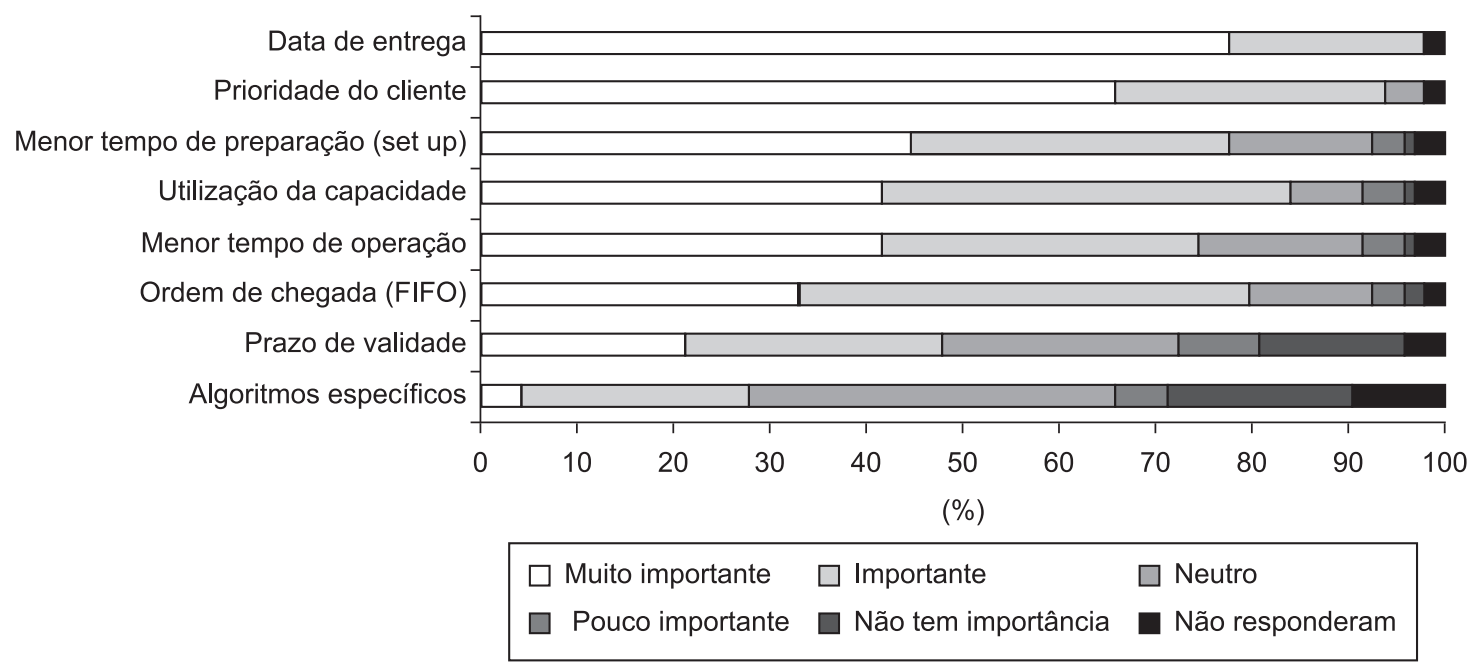

Figura 5. Regras e Critérios utilizados para PDP.

Tabela 3. Controle das ordens de produção.

\begin{tabular}{|c|c|c|c|c|c|c|}
\hline Sistema de apontamento & \multicolumn{2}{|c|}{ MTO } & \multicolumn{2}{|c|}{ MTS } & \multicolumn{2}{|c|}{ Total } \\
\hline Apontamento na ordem de produção & 39 & $70,9 \%$ & 20 & $51,3 \%$ & 59 & $62,8 \%$ \\
\hline Apontamento em terminal de computador na fábrica & 10 & $18,2 \%$ & 11 & $28,2 \%$ & 21 & $22,3 \%$ \\
\hline Apontamento por código de barras & 2 & $3,6 \%$ & 8 & $20,5 \%$ & 10 & $10,6 \%$ \\
\hline Apontamento por sensores automáticos & 3 & $5,5 \%$ & 0 & $0,0 \%$ & 3 & $3,2 \%$ \\
\hline Outros & 1 & $1,8 \%$ & 0 & $0,0 \%$ & 1 & $1,1 \%$ \\
\hline Total & 55 & $100 \%$ & 39 & $100 \%$ & 94 & $100 \%$ \\
\hline
\end{tabular}

A Tabela 5 aponta as principais dificuldades e necessidades relacionadas à PDP.

Mesmo seguindo os procedimentos de Leedy (2000) para a construção do questionário, acabou faltando uma questão aberta para que as empresas respondessem quais os benefícios (reais ou esperados) do uso de uma ferramenta APS. De qualquer forma, em função do número limitado de empresas que usam ou estão em processo de implantação (17 empresas), não se conseguiria uma resposta conclusiva para esta questão. Esta limitação da presente pesquisa aponta para a necessidade de estudos de caso para avaliar melhor esta questão.

\section{Conclusões}

Esta pesquisa teve por objetivo entender as questões que envolvem as práticas adotadas para a atividade de 
Tabela 4. Avaliação da Eficácia do ERP para o PCP.

\begin{tabular}{lr}
\hline $\begin{array}{c}\text { "O Sistema ERP atende às } \\
\text { necessidades do Planejamento } \\
\text { e Controle da Produção?" }\end{array}$ & $\%$ \\
\hline Concordo plenamente & $10,9 \%$ \\
Concordo & $56,3 \%$ \\
Neutro & $20,3 \%$ \\
Discordo & $7,8 \%$ \\
Discordo totalmente & $4,7 \%$ \\
Total & $\mathbf{1 0 0 \%}$ \\
\hline
\end{tabular}

Quadro 3. Comentários finais dos respondentes.

\begin{tabular}{|l|}
\hline \multicolumn{1}{|c|}{ Tópicos citados } \\
\hline Desconhecimento em relação ao APS \\
Atrasos na colocação em uso dos sistemas \\
Dificuldade de personalização \\
Custo do ERP \\
Falta recursos para a atividade propriamente dita \\
Visibilidade do chão de fábrica \\
Dificuldade de redução de estoque em \\
função da imprevisibilidade do mercado \\
\hline
\end{tabular}

Tabela 5. Principais dificuldades e necessidades da PDP nas empresas.

\begin{tabular}{lccccc}
\hline & $\begin{array}{c}\text { Muito } \\
\text { importante }\end{array}$ & Importante & Neutro & $\begin{array}{c}\text { Pouco } \\
\text { importante }\end{array}$ & $\begin{array}{c}\text { Não tem } \\
\text { importância }\end{array}$ \\
\hline $\begin{array}{l}\text { Excesso ou falta de } \\
\text { produto acabado }\end{array}$ & $21.59 \%(19)$ & $43.18 \%(38)$ & $21.59 \%(19)$ & $10.23 \%(9)$ & $3.41 \%(3)$ \\
$\begin{array}{l}\text { Excesso ou falta de estoques de } \\
\text { matérias-primas e componentes }\end{array}$ & $38.20 \%(34)$ & $38.20 \%(34)$ & $17.98 \%(16)$ & $5.62 \%(5)$ & $0.00 \%(0)$ \\
$\begin{array}{l}\text { Dificuldade em prever } \\
\text { data de entrega }\end{array}$ & $24.14 \%(21)$ & $34.48 \%(30)$ & $28.74 \%(25)$ & $10.34 \%(9)$ & $2.30 \%(2)$ \\
$\begin{array}{l}\text { Dificuldade em cumprir } \\
\text { prazo de entrega }\end{array}$ & $25.00 \%(22)$ & $39.77 \%(35)$ & $23.86 \%(21)$ & $10.23 \%(9)$ & $1.14 \%(1)$ \\
$\begin{array}{l}\text { Dificuldade em planejar as } \\
\text { necessidades de materiais }\end{array}$ & $23.60 \%(21)$ & $29.21 \%(26)$ & $30.34 \%(27)$ & $13.48 \%(12)$ & $3.37 \%(3)$ \\
$\begin{array}{l}\text { Dificuldade em priorizar ou } \\
\text { programar ordens de produção }\end{array}$ & $22.99 \%(20)$ & $35.63 \%(31)$ & $26.44 \%(23)$ & $9.20 \%(8)$ & $5.75 \%(5)$ \\
$\begin{array}{l}\text { Dificuldade em controlar a } \\
\text { execução do programa de produção }\end{array}$ & $22.73 \%(20)$ & $34.09 \%(30)$ & $30.68 \%(27)$ & $7.95 \%(7)$ & $4.55 \%(4)$ \\
$\begin{array}{l}\text { Falta de informações organizadas e } \\
\text { confiáveis sobre estrutura de produtos }\end{array}$ & $15.91 \%(14)$ & $27.27 \%(24)$ & $32.95 \%(29)$ & $14.77 \%(13)$ & $9.09 \%(8)$ \\
$\begin{array}{l}\text { Falta de informações organizadas e } \\
\text { confiáveis sobre roteiros e tempos }\end{array}$ & $22.47 \%(20)$ & $33.71 \%(30)$ & $26.97 \%(24)$ & $7.87 \%(7)$ & $8.99 \%(8)$ \\
$\begin{array}{l}\text { Falta de ferramenta de programação } \\
\text { detalhada da produção }\end{array}$ & $30.34 \%(27)$ & $32.58 \%(29)$ & $24.72 \%(22)$ & $8.99 \%(8)$ & $3.37 \%(3)$ \\
\hline
\end{tabular}

programação detalhada da produção e a necessidade de sistemas de programação finita das empresas, como também verificar quais são as barreiras de implantação e os benefícios do uso de ferramentas avançadas de programação detalhada da produção.

Em síntese, verificou-se que os objetivos de maior relevância atualmente para a programação detalhada da produção são a data de entrega e o grau de prioridade do cliente, objetivos que podem ser alcançados mais facilmente com o uso de uma ferramenta de programação finita, de forma complementar aos sistemas MRP/ERP em uso atualmente.

As empresas que adotam o modelo de planejamento MRP, usam planilhas eletrônicas para a programação detalhada e, em geral, estão satisfeitas com o uso dos sistemas de informações gerenciais (sistemas transacionais). Algumas empresas utilizam os SIG há mais de dez anos, indicando certa maturidade no uso deste sistema.

As empresas que pretendem implantar um sistema APS representam cerca de metade das empresas que ainda não dispõem de um APS, o que indica que o MRP não é suficiente na estratégia de produção MTO e, portanto, os APS são sistemas complementares aos sistemas MRP na perspectiva do usuário. Não foi apontada nenhuma empresa que implantou e não obteve resultados satisfatórios, o que indica que os sistemas APS contribuem para os objetivos de desempenho operacional das empresas.

Mesmo com o número limitado de respondentes com sistema APS implantado, algumas respostas (questão aberta) apontam barreiras à implantação na perspectiva dos potenciais usuários (Quadro 3).

No que se refere às dificuldades na implantação de sistemas de programação avançada, comparando-se os dados obtidos neste trabalho com o de Zattar (2004), constatam-se alguns pontos em comum. O levantamento apontou como principais dificuldades a adaptação de procedimentos, necessidade de atualização de cadastros, integração entre sistemas, disciplina em cumprir a programação, capacitação 
do usuário e convencimento da alta administração da necessidade de um sistema complementar.

Destaca-se como limitação desta pesquisa o pequeno número de respostas (95 respostas). Dentre as empresas respondentes, apenas 10 empresas implantaram o sistema APS, impossibilitando uma análise mais profunda das questões Q2 e Q3. Apesar dos cuidados na elaboração e validação do instrumento de pesquisa, faltou incluir duas questões abertas para explorar diretamente as questões referentes às barreiras e benefícios do APS na perspectiva dos usuários.

De qualquer forma, considera-se que os resultados apresentados apontam algumas evidências importantes que são a principal contribuição da presente pesquisa.

\section{Referências}

ASPROVA. Disponível em: <www.asprova.com>. Acesso em: 28 mar. 2010

CORREAA, H.; GIANESI, I. G. N. Just in time, MRPII e OPT. 2th ed. São Paulo: Atlas, 1993.

CORRÊA, H.; GIANESI, I. G. N.; CAON, M. Planejamento, programação e controle da produção. 4th ed. São Paulo: Atlas, 2001.

DUMOND, E. Understanding and using the capabilities of finite scheduling. Industrial Management \& Data Systems, v. 105, n. 4, p. 506-526, 2005. http://dx.doi. org/10.1108/02635570510592398

DURKIN, J. Expert systems: a view on the field. IEE: Expert Systems, p. 56-63, 1996.

ENTRUP, M. L. Advanced planning and scheduling in fresh food industries. Alemanha: Physica-Verlag Heidelberg, 2005.

FERNANDES, F. C. F.; GODINHO FILHO, M. Planejamento e controle da produção. São Paulo: Atlas, 2010.

FRANCISCHINI, P. G.; HECKERT, C. R. Variações do just-in-time na indústria automobilística brasileira. In: ENCONTRO NACIONAL DE ENGENHARIA DE PRODUÇÃO, 18, 1998, Niterói. Anais... Rio de Janeiro: ABEPRO, 1998.

FORZA, C. Survey research in operations management: a process-based perspective. International Journal of Operations \& Production Management, v. 22, n. 2, p. 152-194, 2002. http://dx.doi. org/10.1108/01443570210414310

GOLDRATT, E. M.; COX, J. A meta: um processo de melhoria contínua. 2.ed. Editora Nobel, 2002.

GUNTHER, H.; BEEK, P. Advanced planning and scheduling solutions in process industry. Berlim: Springer-Verlag Heidelberg, 2003.

GRAVES, S.C. A review of production scheduling. Operations Research, v.29, n.4, p.646-675, 1981.

HELO, P. Expectation and reality in ERP implementation: consultant and solution provider perspective. Industrial Management \& Data Systems, v. 108, n. 8 , p. 1045-1059, 2008. http://dx.doi. org/10.1108/02635570810904604

HOPP, W. J.; SPEARMAN, M. L. Factory physics: foundations of manufacturing management. 2th ed. Chicago: Irwin/McGraw-Hill, 2000.
JONSSON, P.; KJELLSDOTTER, L.; RUDBERG, M. Applying advanced planning for supply chain planning: three case studies. International Journal \& Logistics Management, v. 37, n. 10, p. 816-834, 2007. http:// dx.doi.org/10.1108/09600030710848932

LAURINDO, F. J. B.; MESQUITA, M. A. Material requirements planning: 25 anos de história. Gestão\&Produção, v. 7, n. 3, p. 320-337, 2000. http:// dx.doi.org/10.1590/S0104-530X2000000300009

LEEDY, P. D. Practical research: planning and design. 7th ed. Nova Jersey: Prentice-Hall, 2000.

LIN, C. H.; HWANG, S. L.; WANG, E. M. Y. A reappraisal on advanced planning and scheduling systems. Industrial Management \& Data Systems, v. 107, n. 8 , p. 1212-1226, 2007. http://dx.doi. org/10.1108/02635570710822822

LINTER. Disponível em: <www.linter.com.br>. Acesso em: 28 mar. 2010.

LUSTOSA, L. J. et al. Planejamento e controle da produção. Rio de Janeiro: Elsevier, 2008.

METAXIOTIS, K. S.; PSARRAS, J. E.; ERGAZAKIS K. A. Production scheduling in ERP systems: an AI-based approach to face the gap. Business Process Management Journal, v. 9, n. 2, p. 221-247, 2003. http://dx.doi.org/10.1108/14637150310468416

ORTEMS. Disponível em: <www.ortems.com.br >. Acesso em: 28 mar. 2010.

PACHECO, R. F.; CÂNDIDO, M. A. B. Uma metodologia para a seleção de sistemas de programação da produção com capacidade finita. In: ENCONTRO NACIONAL DE ENGENHARIA DE PRODUÇÃO, 22. Curitiba, 2002. Anais... Rio de Janeiro: ABEPRO, 2002.

PACHECO, R. F.; SANTORO, M. C. A Adoção de modelos de scheduling no Brasil: deficiências do processo de escolha. Gestão \& Produção,v. 8, n. 2, p. 128-138, 2001.

PEDROSO, M. C.; CORREA, H. L. Sistemas de programação da produção com capacidade finita: uma decisão estratégica? Revista de Administração de Empresas, v. 36, n. 4, p. 60-73, 1996.

PPI-MULTITASK. Disponível em:<www.ppi-multitask. com.br> Acesso em: 28 mar. 2010.

PREACTOR INTERNATIONAL. Disponível em: <www. preactor.com>. Acesso em:28 mar. 2010.

QUINTIQ. Disponível em: <www.quintiq.com>. Acessoem: 28 mar. 2010.

STADTER, H.; KILGER, C. Supply chain management and advanced planning: concepts, models, software and case studies. 3th ed. Berlim: Springer, 2005.

TAAL, M.; WORTMANN, J. C. Integrating MRP and finite capacity planning. Production Planning \& Control, v. 8, n. 3, p. 245-254, 1997. http://dx.doi. org/10.1080/095372897235307

TAYLOR. Disponível em: <www.taylor.com>. Acesso em: 28 mar. 2010.

ZATTAR, I. C. Análise da aplicação dos sistemas baseados no conceito de capacidade finita nos diversos níveis da administração da manufatura através de estudo de caso. 2004. 136 f. Dissertação (Mestrado em engenharia mecânica)-Universidade de Santa Catarina, Florianópolis, 2004.

WIERS, C. S. V. A case study on the integration of APS and ERP in a steel processing plant. Production Planning and Control, v. 13.n. 6, p. 552-560, 2002. http://dx.doi. org/10.1080/09537280210160321 